agreement indicate that "pattern recognition" of HRM/EPT was not adequate and highlighted the value of objective metrics in diagnosis of esophageal dysmotility.

Competing interests $M$ Fox consultant for: given imaging, paid instructor for: Sandhill MMS, J Pandolfino: None declared, J Jafari: None declared, D Menne: None declared.

\section{OC-155 NO WAY BACK-IRREVOCABLE ALTERATION OF THE GASTRIC AND OESOPHAGEAL MICRO-ENVIRONMENT FOLLOWING CHOLECYSTECTOMY}

doi:10.1136/gutjnl-2012-302514a.155

S N S Gilani, ${ }^{*}$ G Bass, T N Walsh. RCSI Academic Department of Surgery, Connolly Hospital, Dublin, Ireland

Introduction Background: Loss of the gallbladder reservoir function at cholecystectomy may critically alter the dynamics of bile storage and release. Consequent iatrogenic duodeno-gastro-esophageal reflux (DGER) may be associated with oesophago-gastric adenocarcinoma. Aims To examine the histological and molecular effects of cholecystectomy-induced DGER on gastric and oesophageal mucosae.

Methods Patients and Methods: In a retrospective study we compared 26 gallstone-free controls with 25 patients pre-cholecystectomy and 29 patients post-cholecystectomy for one or more years. In a prospective study we compared 26 controls with 25 patients before and within 1 year of cholecystectomy. All underwent oesophago-gastro-duodenoscopy (EGD) with biopsies from the antrum, esophagogastric junction (EGJ) and $5 \mathrm{~cm}$ above the EGJ. A histochemical bile reflux index (BRI) was calculated and immunohistochemistry was performed for p53 and Ki67.

Results Results: In the retrospective study antral BRI positivity was $11 \%$ in controls vs $69 \%$ in cholecystectomy patients ( $p=0.001$ ); at the EGJ BRI positivity was $19 \%$ in controls vs $41 \%$ in cholecystectomy patients $(\mathrm{p}=0.032)$. $\mathrm{p} 53$ was expressed at the antrum in $4 \%$ of controls vs $52 \%$ cholecystectomy patients $(\mathrm{p}=0.001)$ and in $19 \%$ vs $66 \%$ at the EGJ ( $p=0.001)$. Ki67 was expressed at the antrum in $23 \%$ vs $59 \%(p=0.001)$ and at the EGJ in $19 \%$ vs $62 \%(p=0.001)$. Prospectively, BRI positivity increased from $11 \%$ to $36 \%(p=0.04)$ at the antrum within 1 year of cholecystectomy. Ki67 expression increased from $19 \%$ to $48 \%(p=0.044)$ at EGJ in patients within 1 year of cholecystectomy while p53 remained unchanged.

Conclusion Changes attributable to DGER occur early in the gastric and LES mucosae of patients following cholecystectomy. Ki67 and p53 over-expression suggests that these changes may be precursors of malignant transformation. Such concerning changes suggest that options other than cholecystectomy be considered for patients with gallstones in a functioning gallbladder.

Competing interests None declared.

\section{DDF symposium: "bowel cancer screening"}

\section{OC-156 ANALYSIS OF COLORECTAL POLYPS DETECTED IN THE ENGLISH NHS BOWEL CANCER SCREENING PROGRAMME WITH EMPHASIS ON ADVANCED ADENOMA AND POLYP CANCER DETECTED}

doi:10.1136/gutjnl-2012-302514a.156

${ }^{1} \mathrm{D}$ Majumdar, ${ }^{*}{ }^{2} \mathrm{~J}$ Patnick, ${ }^{2} \mathrm{C}$ Nickerson, ${ }^{1} \mathrm{M} \mathrm{D}$ Rutter. ${ }^{1}$ Department of Gastroenterology, University Hospital of North Tees, Stockton on Tees, UK; ${ }^{2}$ NHS Cancer Screening Programmes, NHS Cancer Screening Programmes, Sheffield, UK

Introduction Colorectal cancer is the second most common cause of cancer related death in the UK causing around 16000 deaths each year. Colorectal adenomas are slow growing precursor lesions which progress to cancer. The lesion of most interest in this context is advanced adenoma (size $10+\mathrm{mm} /$ with $20 \%-25 \%$ villous histology/ high grade dysplasia) as they are of higher risk of progression (2). This study analysed adenomatous lesions detected in NHS BCSP programme.

Methods Data on each patient entering the NHS BCSP programme is prospectively recorded on the national BCSP database. The database was interrogated for all polyps/adenomas found during the period September 2006 to September 2011. The data were analysed with particular focus on detection of advanced adenoma and polyp cancers. Results A total of 65535 polyps were found, of which 43954 $(67.06 \%)$ were confirmed histologically as adenomas. 15261 advanced adenomas were detected. These accounts for $34.7 \%$ of lesions removed and $23.9 \%$ of all lesions detected during screening. 842 polyp cancers were found and removed. $1.9 \%$ of the adenomatous lesions removed were polyp cancer. The incidence of villous morphology, HGD and polyp cancer, categorised by adenoma size, are shown in the Abstract OC-156 table 1. The presence of villous histology and high grade dysplasia increases with increasing size of adenoma, whereas villous histology begins to plateau for adenomas over $15 \mathrm{~mm}$ in size, the incidence of HGD appears linear up to and beyond adenomas of $45 \mathrm{~mm}$ in size.

Abstract OC-156 Table 1 Advanced histological feature and cancer in different size groups of polyp

\begin{tabular}{llllllll}
\hline & $\begin{array}{l}\text { Total } \\
\text { number } \\
\text { of adenoma }\end{array}$ & $\begin{array}{l}\text { Polyp } \\
\text { cancers }\end{array}$ & $\begin{array}{l}\% \text { Of polyp } \\
\text { cancer }\end{array}$ & HGD & $\begin{array}{l}\text { \% Of } \\
\text { HGD }\end{array}$ & $\begin{array}{l}\text { Villous } \\
\text { histology }\end{array}$ & $\begin{array}{l}\text { \% Of villous } \\
\text { histology }\end{array}$ \\
\hline & 18533 & 31 & 0.16 & 152 & 0.8 & 1035 & 5.5 \\
$5-9 \mathrm{~mm}$ & 9577 & 48 & 0.5 & 299 & 3.1 & 1781 & 18.6 \\
$10-14 \mathrm{~mm}$ & 5159 & 193 & 3.7 & 609 & 11.8 & 2381 & 46.1 \\
$15-19 \mathrm{~mm}$ & 3055 & 181 & 5.9 & 567 & 18.5 & 1904 & 62.3 \\
$20-24 \mathrm{~mm}$ & 1540 & 102 & 6.6 & 408 & 26.4 & 1048 & 68.0 \\
$25-29 \mathrm{~mm}$ & 683 & 70 & 10.2 & 211 & 30.9 & 511 & 74.8 \\
$30-34 \mathrm{~mm}$ & 401 & 48 & 11.9 & 139 & 34.6 & 299 & 74.5 \\
$35-39 \mathrm{~mm}$ & 115 & 21 & 20 & 42 & 36.5 & 93 & 80.8 \\
$40-44 \mathrm{~mm}$ & 138 & 20 & 14.4 & 54 & 39.5 & 106 & 76.9 \\
\hline
\end{tabular}

Conclusion $67.06 \%$ of all lesions found were histologically confirmed colorectal adenomas. One third of adenomas were advanced adenomas. There is a trend of increase of incidence of cancer and features of advanced neoplasia in adenomas with increasing size. The incidence of AA feature present in lesions below $10 \mathrm{~mm}$ in size was $10.07 \%$.

Competing interests None declared.

\section{REFERENCES}

Office of National Statistics. UK, 2010.

2. Atkin W, Marson B, Cuzick J. Long term risk of colorectal cancer after excision of ectosigmoid adenomas. N Engl J Med 1992;326:658-62.

\section{BSG symposium: "stem cells" \\ OC-157 PHYSIOLOGICAL CHANGES IN MATRIX STIFFNESS MODULATE HEPATIC PROGENITOR CELL MORPHOLOGY, PROLIFERATION AND DIFFERENTIATION}

doi:10.1136/gutjnl-2012-302514a.157

${ }^{1} \mathrm{~T}$ T Gordon-Walker, ${ }^{2}{ }^{2} \mathrm{~J}$ Schrader, ${ }^{1} \mathrm{~L}$ Boulter, ${ }^{1} \mathrm{~A} J \mathrm{~J}$ Robson, ${ }^{1} \mathrm{~S} J$ J Forbes, ${ }^{3,4} \mathrm{R}$ G Wells, ${ }^{1} \mathrm{~J}$ P Iredale. ${ }^{1}$ MRC Centre for Inflammation Research, Queen's Medical Research Institute, Edinburgh, UK; ${ }^{2}$ Department of Medicine I, University Medical Center Hamburg-Eppendorf, Hamburg, Germany; ${ }^{3}$ Department of Medicine, School of Medicine, University of Pennsylvania, Philadelphia, USA; ${ }^{4}$ Department of Gastroenterology, School of Medicine, University of Pennsylvania, Philadelphia, USA

Introduction Liver injury is associated with changes in the biochemical and physical properties of the extracellular matrix 